\title{
Lean Information Processing in the Specification Process
}

- Using operational data to enable real mass customization

\author{
Carsten Svensson \\ Enterprise Integration, Inc., 5971 Kings Towne Village Parkway, \\ Alexandria, Virginia, USA
}

\begin{abstract}
To improve the overall efficiency, from a supply chain perspective, manufactures are focusing their activities around a limited number of coreprocesses. Consequently the internal processing degree is reduced. When the degree of internal processing is reduced, the organizational balance between manufacturing processes and cross-organizational integration processes shifts, and this is reflected in the cost drivers. The reality is that while the cost of direct manufacturing is reduced, business processes becomes major cost drivers. This is a radical shift from conventional industry where the cost drivers typically were associated with the transformation of material. This paper will argue that focusing on production optimization have become less important to the end-manufacturer because the industrial paradigm have change. Instead the ability to orchestra the manufacturing of customized products presents a significant potential for efficiency improvement. In acknowledgement of this trend manufacturing concepts such as lean are successfully being applied to administrative processes such as the product specification process.
\end{abstract}

\section{Introduction}

Manufactures of end products have, in regions with high wages and limited access to raw material, evolved in to assembly plants, development centers and administrative offices. In most cases, the company names are still the same the products better than ever, and the majority of the population is still employed. So what happened? Instead of transforming material the companies and people are transforming information.

This paper will focus on the information transformation associated with the vision of manufacturing products adapted to the individual customer, at the cost of a mass produced product, also called mass customization.

A typically example of the change from manufacturing to a knowledge economy is Denmark. A large portion of the industrial production is heavy machinery such as

Please use the following format when citing this chapter:

Svensson, C., 2008, in IFIP International Federation for Information Processing, Volume 257, Lean Business Systems and Beyond, Tomasz Koch, ed.; (Boston: Springer), pp. 347-354. 
wind turbines, cement factories, printing presses, powder processing plants, homogenizers etc. these products are typically highly specialized and customized. These manufactures have often started out as machine shops with a good idea and have over time evolved into world leaders within their respective niche fields. As the products have become more complex these manufactures focused their production to a point where they only manufacture a few key components were as the majority of generic components are bought from large supplier networks. The background for this trend is that in order to remain competitive manufacturers have through the last 20 years been going through a focusing process [16]. The internal degree of processing have been reduced leaving only a limited core activities in house [15] as a result the ability to control and coordination supply chains have become the core functions of the company, but it is a core function with low visibility. Endmanufacturers are currently realizing that the ability to process information may become the single most important process, as specialized suppliers carry out the majority of the physical processing, and consequently lean projects in the conventional sense are not meaning full. However lean information processes are of value as they address the main processes of modern corporations.

\section{The Deficiencies of Push- and Pull Production}

For the end-manufacturer specializing in BTO (Build To Order) products, the transition from being a manufacturer mastering a production process to being a supply network manager and distributor of information is challenging both with regards to operations and organization, because a new set of product data and production data have to be generated for every product. Consequently many manufacturers have been looking to the concept of mass customization. With regards to mass customization there has been a tendency to focus on the market value of customization (e.g.[1],[4],[6],[12],[13]\&[14]) rather than the need demanding operational preconditions [19]. Especially "build to order" manufacturers have underestimated the need for operational skills and believed that mass customization would be a short cut to a larger market rather than a manufacturing strategy much more complex than mass production or craft manufacturing. Consequently delivering the customized product has proven to be a problem for manufacturers of customized goods, in relation to cost and time [19].

In conventional mass production the finished goods inventory absorb the variations in the market demand; thereby it is possible to enable a high utilization of the production system. However the inventory or lack thereof is the soft spot of this production from, and as it will later be demonstrated customized products have the potential to compete, because with the combination of iterative configuration and an integration of planning and selling it is possible to ensure a high utilization of the production system without an inventory of finished goods.

In systems where the value of the products are high relative to the production system or where the products are customized, a pull system can be applied to compensate 
for the variations in demand and product-structure, consequently the production system must be flexible, to address these challenges.

In a BTO production, which per definition is a pull system, the order specification process (figure 1) can be a major cost driver [8]. To realize the vision of mass customization the BTO unique cost associated with specifying the product will have to be kept at a minimum, and to improve the efficiency, lean administrative processes supported by technology can be applied. Customization might create unique value for the customer resulting in a strong competitive position, but often customized products are disqualified from the market by the basic product attributes cost, quality and delivery time. A large portion of this cost is associated with the engineering and administration of the specification process which will have to bed done of each individual product compared to mass production where the specification cost is distributed over all the products of a production run.

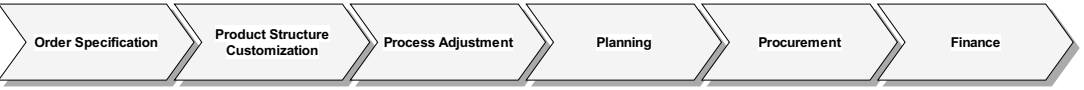

Fig. 1. A generic example of the specification process (Based on Barfod \& Hvolby[3])

This situation is very different from mass production, because variations are most often absorbed by the production system. The result is often a low utilization of the productions system. Observation from seven profitable manufacturers indicates that a utilization of the production system less than $50 \%$ is not uncommon, thereby paralyzing the competitiveness compared to mass production. And in addition manufactures are compensating for long delivery times by to carry and inventory of less used and expensive components [14] leading to an annual inventory overturn (value) of less than two. The background for the low utilization the production system in a build to order context, can be found in the insufficient distribution of workload. Bottleneck machines are often overloaded but because this information is not available when new products are being customized in the sales situation, no action is taken to sell configurations that are not utilizing overloaded equipment or choosing modules in inventory over modules that have to be ordered, despite there will be no functional difference in the customers perception of the product.

To avoid these BTO compensation models information management tools can be applied to manage the customization process based on customer value, thereby creating a production situation more similar, in transparency, to the one of a mass production manufacturer, by enabling a higher utilization of inventory and production system, without sacrificing throughput time and cost.

In the order specification phase the manufacturer is giving the customer a promise without knowing the precise workload on the machines and which components are in stock. Consequently the actual delivery time and cost is unknown. Decisions are often based on experience and intuition instead of operational data. To 
reach an acceptable level of efficiency this craft based approach must be replaced with decisions based on facts, and this can only be done through and industrialization process, where data is structured, and formatted for reuse.

One of the major reasons that the production - and inventory systems are not used to it fullest is the lack of valid information since precise data have never been so critical as with customized products [5]. Lack of valid data has proven to be a problem for manufacturers of customized products [10], and without accurate data efficient production, not to mention mass customization, is not feasible.

\section{Tools Supporting Mass Customization}

However the tools to realize the full potential of mass customization are available. Configurators have proven to be capable of handling constraints determined by structural and business rules, and Advanced Planning Systems (APS) have demonstrated the capability to optimize manufacturing and inventory management for fixed product structures, however APS and configurators are currently trapped in sales- and planning stove pips.

Since the days of Henry Ford information systems have had a tendency to be build as vertical stovepipes based on organizational boarders, and this is also true for the specification process. Currently state of the art offers integrated solutions within an area e.g. structural design where we have seen how configurators have revolutionized the structural adaptation, APS systems have provided production planners with tools that will enable them to optimize production and lean projects have the potential to revolutionize business processes by overcoming the barriers of data silos allowing a process orientated cross organizational integration to the direct benefit of the customer. But these improvements will only fulfill their full potential when they are integrated, and data can travel freely between them. In this paper will be looking at configurators and planning systems as mass customization enabling technologies. From a lean perspective these technologies plays a critical role in delivering value to the customer. The customer perceived value when it comes to mass customization is primary the improved functionality relative the cost and delivery trade of. By applying the methods suggested, the balance will be tipped towards lower cost and shorter delivery times to a point where cost is not only comparable to mass produced products but lower, and delivery time is acceptable, and can become a parameter that is a function of cost. This goes beyond what Pine [13] setup as the initial vision. The key to realizing this potential will be through the dynamic utilization of inventory as well as production capacity allowed through the integration of advanced planning systems and product configurators.

The use of configurators has improved the efficiency of the specification process radically [9].

The typically consequences of installing configurators are [2],[7]: 
- Reduced adaptation time

- Increased customer satisfaction

- Increased uniformity in solutions

- Fewer technical problems

- Improved enquiry to order ration

- Engineering focus on long term development

- Better opportunity for accurate planning

By using a configurator the customer can improve the structural design through an iterative decision process. By switching modules the customer can easily work on perfecting the solution, thereby getting the best possible solution, for the customer that is. The price calculation is based on the exploded BOM, where each unit used is priced. After the configuration is locked the order is entered in to the back office system. The configurator is a static representation of the knowledge in the operational system. By holding this knowledge in a configurator, it is easily accessible. Being a static representation, the configurator holds no knowledge regarding the dynamics of the operational system, thereby providing insufficient knowledge regarding the materialization process.

The price calculation of most configurators is based on the exploded BOM (bill of material), where each unit used is priced using a list price thereby the actual not representing the actual manufacturing cost, but most often a best case scenario. This pricing model is totally inadequate for mass customization build to order product, because a BOM do not reflect the manufacturing context at the time of production, so ensuring profitability is at best a gamble.

If we look at the current state of the art specification processes, the sales process is completed and the configuration is locked the order is entered in to the back office system. Leading software companies (SAP R/3 APO, Oracle business suite) have solutions that can provide a delivery date estimation based on an ATP (available to promise)[11]. The problem of this approach is the assumption that the production system is a stable system with fixed through put times and production cost. This is far from the case especially in "build to order" production where the workload is constantly shifting. Especially, if the number of units is low, the fluctuations will constantly be altering the cost and throughput times. Giving an ATP is a step in the right direction, but it is a one way communication thereby leaving little room for optimization, and no information about the actual cost of the product. But it is not possible to consider production data as variables equal to the modules of a customized product.

The key to eliminating the stove pipes is a performance based approach to product configuration. Instead of conventional configuration where the customer chooses a set of modules, the customer defines a performance criteria. For a homogenizer that might be volume/hr. max/min temp., and desired pressure. These requirements then constrains the solution space initially. Within the constraint solution space the customer chooses to optimize based on criteria's such as delivery time, cost, potential for upgrades etc. 
Basically this method is a iterative compared to the conventional waterfall approach. By pulling the information from the APS system into the configuration it will be possible to calculate the lowest production cost and delivery time based on workload and current inventory under the constraints of customers performance requirements and the structural solution space.

In the approach illustrated in figure 2, the first step is that the combination of modules that meet the customers functional requirements is calculated. An initial subset of product structures are the submitted to the planning system based on lowest estimated/average cost and delivery time. These product structures are then submitted to the planning system where actual cost and delivery time is calculated, and within these product structures, structures that contains components manufactured on bottleneck machines are the modules are replaced with components manufactured on non-bottleneck machines. Components that are not in inventory are replaced with components in inventory (with a cost similar to the original component and purchasing cost if the delivery is optimized based on cost) additionally components with a high inventory overturn can be replaced with components with a low inventory overturn to keep a current inventory etc..

Then the configuration is presented to the customer and the customer can then chooses an alternative modules for each selected module and the customer can select among valid alternatives and the consequences will be recalculated.

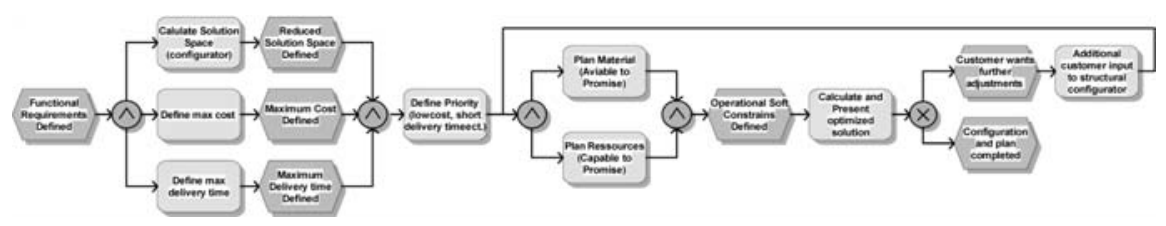

Fig. 2. An example of the iterative process of configuration and planning that allows optimized utilization of inventory and capacity.

By having direct access to the tradeoffs that are made in the customization process it will be possible to optimize the utilization of inventory and production. This can be achieved if the data from the planning system can be integrated in the configurator, thereby the customer and manufacturer can find a solution that is mutual beneficial. The customer will get lower prices as the manufacturer can improve inventory turnover and utilization of the production system. An application of the production data in the sales situation can be an optimization of the configuration against delivery time.

By prioritizing the utilization of existing inventory over purchases and utilization of available production equipment over bottleneck machines, it is possible to configure a solution that is optimized from both a manufacturer and customer perspective, and potentially the cost can be significantly lower than conventional 
BTO production where inventories rapidly become obsolete and the distribution of work load is poor, and this is enabled by integrating sales data with operational data over the organizational boundaries.

The reason why this is optimization is possible is that the configuration is based on functional requirements rather than the conventional approach of using the product structure, so instead of focusing on components used, it would focus on what the customer is going to use the product for as described in [17],[18].

\section{Conclusion}

In the modern manufacturing organization information have become the key to profitability. Integrated digital order processing significant potential, currently the majority of order realization processes are still manually operated or only supported by stovepipe legacy systems. This is probably related to complexity and our historical inability to align cross-functional software solutions with business processes. This paper demonstrates how cross-functional business processes may be aligned with product specification systems in a cross organization environment by integrating planning systems and configuration systems thereby providing an end-toend integrated and an automated solution to the built to order challenge. As an outcome the potential market for customized products will expand, through a reduction in administrative and manufacturing cost. Ideally the IT-infrastructure would be laid out to accommodate this type of operation, unfortunately there is often a disconnect between the actual task and the IT landscape. This paper suggests that the current scope of IT-systems is often misaligned with the implications of lean business processes and consequently the true potential of mass customization is not realized. This paper has described how mass customization potentially has an efficiency potential that goes beyond what Pine [13] setup as the initial vision. The key to realizing this potential will be through the dynamic utilization of inventory as well as production capacity allowed through the integration of advanced planning systems and product configurators.

\section{References}

1. Agrawal, M., Kumaresh, T.V and Mercer, G. A. (2001). The false promise of mass customization; The McKinsey quarterly, $\underline{3}$, 62-71.

2. Bonehill E. and Slee-Smith P. (1998). Product configurators. Responsiveness in manufacturing. IEE. 213.

3. Barfod, Ari and Hvolby, Hans-Henrik (1994): Administrative Rationalisation by Applying Activity Chains". Issues of Integration in Manufacturing, 9th IPS Research Seminar, Department of Production, Aalborg University, April. 
4. Boynton, A.C. Victor, B. and Pine, B.J. (1993). New competitive strategies: challenges to organization and information technology, IBM systems Journal, $\underline{32}$, 1993.

5. Eastwood, M. A. (1996). Implementing mass customization. Computers in industry, 20, 171-174.

6. Gilmore, J. H. and Pine II, J.B. (1997). The four faces of mass customization, Harvard Business Review, 75(1), 91-102.

7. Horneys, D. (1993). A better way to “build to order”. Machine design, august 13.

8. Hvam, L. Have, U. (1998). Re-engineering the specification process. Business process management journal, $\underline{4(1)}$.

9. Hvam L., Riis J., Malis, M. and Hansen B. (2000). A procedure for building product models. Proceedings, PM (Product models) Linköbing.

10. Hvolby, H.H. and Barfod A. (1998). Design of integration in manufacturing. Proceedings of the 13'th IPS Research Seminar, Denmark..

11. Knolmayer G., Mertens P. and Zeier A.. (2002) Supply Chain Management Based on SAP Systems, Order Management in Manufacturing Companies, Springer.

12. Kotha Suresh. (1995). Mass customization: implementing the emerging paradigm for competitive advantage. strategic management journal, 16, 21-42.

13. Pine II, J.B. (1993). Mass customization, the new frontier in business competition, Harvard business school press, Boston.

14. Pine, J. Victor B. Boynton A. (1993) Making Mass customization work. Harvard Business review, 108-119.

15. Prahalad, C.K.and Hamel G. (1990). The core competence of the corporation. Harvard Business Review, may- june. 79-91.

16. Skinner, W. (1974) The focused factory. Harvard Business Review. may-june. 113-121.

17. Svensson, C. (2002) Experiences from implementing a low cost configurator,The 5th International SMESME Conference. Danbury .

18. Svensson, C. and Jensen, T. (2003) Mass Customization for Competitive Advantage, edited by Mitchell M. Tseng and Frank T. Piller, to be published by Springer.

19. Zipkin, Paul. (2001). The limits of mass customization. MIT Sloan management review, spring, $81-88$. 